\title{
TO STUDY THE PREVALENCE AND CLINICAL PROFILE OF CHRONIC ATRIAL FIBRILATION IN HOSPITALIZED PATIENTS
}

\author{
Dharma Rao V. ${ }^{1}$, Rajaneesh Reddy M. ${ }^{1}$, Srikanth K. ${ }^{1}$, Raj Kumar Prakash B. ${ }^{1}$, \\ Satya Prasad A. ${ }^{2} \&$ Guru Prasad S.S. ${ }^{3}$ \\ ${ }^{1}$ Department of General M edicine, ${ }^{2}$ Department of Pulmonary M edicine, ${ }^{3}$ Department of Radiodiagnosis, \\ Mamata Medical College \& General Hospital, Khammam, Andhra Pradesh. \\ Correspondence: \\ Dharma Rao V. \\ Professor, Department of General Medicine, Mamata M edical College \& General Hospital, \\ Khammam, Andhra Pradesh. E-mail: mamatakhmm@gmail.com
}

\section{Abstract :}

Objective : To determine the prevalence of chronic atrial fibrillation (AF) in a tertiary care center and to identify the clinical profile of chronic AF in hospitalized patients.

Methods : All patients admitted to M amata General Hospital in medicine/cardiology wards with chronic AF (persistent and permanent) during the period January 2012 to December 2012 were included into the study. The principal exclusion criteria were new onset AF and acute AF.

Results : During the study period, 49 patients were admitted with chronic AF with an average of 45.44 years. A slight female dominance was seen with male: female ratio of 1:1.2. Half of the patients (51\%) were below the age 50 years. The elderly age group comprised of only $16.3 \%$ of cases. The commonest presenting complaint was dyspnea followed by pal pitation. Rheumatic valvular heart disease was seen more commonly in people below the age of 50 years whereas hypertension and ischemic heart disease after 50 years. Heart failure was the commonest condition asso ciated with the chronic AF and was the cause of hospitalization in almost fifty percent of cases

Conclusions: Chronic AF is still a cause of concern in India in people below the age of 50 years due to high prevalence of rheumatic fever inspite of advances in the medical field.

Keywords : Chronic Atrial Fibrillation, RHD

\section{Introduction :}

Atrial fibrillation is the most common clinically significant cardiac arrhythmial. Cardiac co-morbidities that are associated with AF include hypertension, coronary artery disease (CAD), valvular heart disease (VHD), congestive heart failure (CHF), cardiomyopathy, pericarditis, congenital heart disease (CHD) and cardiac surgery2 9. Noncardiac co morbidities that are associated with AF include acute pulmonary embolism, chronic obstructive pulmonary disease (COPD), obstructive sleep apnea,

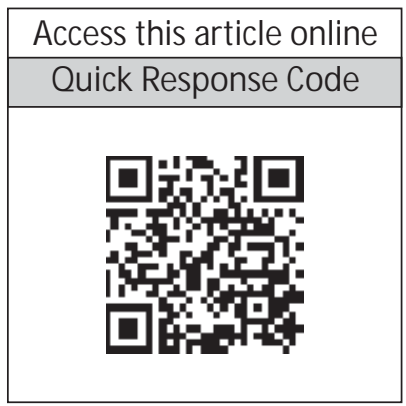

prevalence of $\mathrm{AF}$ is influenced by age, gender, 456 cardiovascular disease (CVD) such as valvular heart disease, and CV risk factors such as hypertension, diabetes, 7 obesity, 8 and insulin resistance. 9 It was calculated that currently more than 3 million inhabitants of the USA suffer from atrial fibrillation and that this will increase to more than 7 million by 2050.15 Comparable figures for India are not available.

Knowing the prevalence of atrial fibrillation and documentation of medical management are important in the provision of primary care. This study sought to determine the prevalence of chronic atrial fibrillation in a tertiary care center and to identify the clinical profile of chronic AF in hospitalized patients.

\section{Methods and Material :}

All patients admitted to Mamata General Hospital in medicine/cardiology wards with atrial fibrillation during 
the period January 2012 to December 2012 were the potential subjects. The principal inclusion criteria were a clinical diagnosis of chronic atrial fibrillation (persistent and permanent). The principal exclusion criteria were new onset AF and acute AF. The baseline data on cardiovascular diseases, respiratory diseases and other pertinent aspects of the medical history obtained by means of questionnaire.

Diagnosis of AF: AF was diagnosed based on the routine 12-lead electrocardiogram (ECG) records during the hospitalization.

Patients with documented AF were classified into two subgroups based on their first ECG recorded on arrival in either Emergency Department or Coronary Care Unit. An ongoing AF group included patients who had either chronic AF or developed AF before admission and a new-onset AF group consisted of patients who developed AF during hospitalization.

The presence of atrial fibrillation was based on documentation in the continuous patient profile, the clinic notes, consultant letters, emergency department or hospital discharge summaries, electrocardiograms, Holter monitor reports, echocardiograms, or stress test reports.

Chronic Atrial Fibrillation is defined as longer than 7 days for this study.

I Persistent AF - Episodes of AF persisting more than 7 days and require either pharmacologic or electrical intervention to terminate

I Permanent AF - Continuous AF, that has failed cardioversion, or where cardioversion has never been attempted

\section{Results:}

A total of 87 potential patients who were hospitalized in the medicine department/cardiology department of M amata General Hospital were screened for the study. Of these, 49 were found to be eligible. The main reason for exclusion was new onset of AF and AF which lasted for less than 7 days.

\section{Age and Sex Distribution}

In this study, the patients were aged 18 years to 85 years with an average of 45.44 years. The maximum number of cases were found between 40 to 60 years $(n=26,53 \%)$ with an average of 48 years. Half of the patients ( $n=25,51 \%)$ were below the age of 50 years. Elderly age group comprised of less than 20 percent of cases (i.e.16.3\%) (Table. 1)

In our study, $44.9 \%$ were male patients and $55.1 \%$ were females. This reflects the female dominance of the disease and current epidemiology of chronic AF in this part of Andhra Pradesh. Highest number of cases was seen in 30 60 years age group in case of females and in 40-60 years age group in case of males. The male and female ratio was 1:1.2

Atrial fibrillation patients with rheumatic etiology commonly presented below 50 years but HTN and IHD presented after 50 years.

\section{Presenting Features}

The commonest presenting complaint in our study was dyspnea followed by palpitation (Table. 2). The duration of symptoms ranged from 15 days to 20 years. Shorter duration was noticed in cases of Ischemic Heart Disease and longer duration in Rheumatic Heart disease.

\section{Associated conditions with AF}

CCF was the commonest condition associated with the chronic AF and was the cause of hospitalization in almost fifty per cent of cases (Table. 3).

\section{Etiology}

In this study rheumatic heart disease (75.51\%) is the most common cause followed by ischemic heart disease (10.20\%) and hypertension (6.12\%) (Table. 4)

Table no 1: Age and sex distribution of atrial fibrillation

\begin{tabular}{|l|c|c|c|c|}
\hline Age Group & Male & Female & Total & Percentage \\
\hline $10-20$ & 1 & 1 & 2 & 4.08 \\
\hline $20-30$ & 3 & 2 & 5 & 10.2 \\
\hline $30-40$ & 2 & 6 & 8 & 16.32 \\
\hline $40-50$ & 4 & 6 & 10 & 20.4 \\
\hline $50-60$ & 9 & 7 & 16 & 32.65 \\
\hline $60-70$ & 1 & 3 & 4 & 8.16 \\
\hline $70-80$ & 2 & 1 & 3 & 6.12 \\
\hline$>80$ & - & 1 & 1 & 2.04 \\
\hline
\end{tabular}


Table No 2: Clinical presenting features of atrial fibrillation

\begin{tabular}{|l|c|c|}
\hline Complaint & No. of patients & Percentage \\
\hline Dyspnoea & 41 & 83.67 \\
\hline Palpitations & 26 & 53.06 \\
\hline Pedal edema & 13 & 26.53 \\
\hline Chest pain & 15 & 30.61 \\
\hline Haemoptysis & 1 & 2.04 \\
\hline Paralysis & 6 & 12.24 \\
\hline
\end{tabular}

Table No 3: Associated conditions with atrial fibrillation

\begin{tabular}{|l|c|c|}
\hline Associated condition & No. of patients & Percentage \\
\hline 1. CCF & 24 & 40 \\
\hline 2. Angina & 8 & 13.33 \\
\hline 3. Embolic stroke & 8 & 13.33 \\
\hline 4.Haemoptysis & 1 & 1.6 \\
\hline 5. Infective endocarditis & 1 & 1.6 \\
\hline
\end{tabular}

Table no 4: Etiology of atrial fibrillation

\begin{tabular}{|l|c|c|c|}
\hline S. No. & Complaint & No. of patients & Percentage \\
\hline 1 & RHD & 37 & 75.51 \\
\hline 2 & IHD & 5 & 10.20 \\
\hline 3 & HTN & 3 & 6.12 \\
\hline 4 & DCM & 2 & 4.08 \\
\hline 5 & CHD & 1 & 2.04 \\
\hline 6 & COPD & 1 & 2.04 \\
\hline
\end{tabular}

Discussion :

In the present study, AF was seen more common in the 20 50 age group. This is in contrast to that reported by other authors. According to Lip Gy, Golding DJ majority of people fibrillated after the age of 50 years. ${ }^{16}$ Epidemiological studies have shown that AF is fairly uncommon in people aged under 50 years but is found in $0.5 \%$ of people of aged 50-59, increasing to $8.8 \%$ at age $80-89 .{ }^{17}$ PT Onundarson et al showed that the prevalence of chronic AF is low in randomly selected population 32-64 years of age. ${ }^{18}$ These differences are because of the etiological cause of chronic AF. Nowadays ischemic heart disease is the most prevalent cardiac disease related with the development of AF in the western countries. In the present study the rheumatic heart disease is still the common etiology.

In the present study the sex ratio of female to male is 1.22:1, AF with valvular disease being more frequent among women than men. According to Lok NS, Lan CP, the ratio is 1.8:1. In these studies the female predominance is there. ${ }^{19}$

In the present study dyspnea (83.67\%), palpitations $(53.06 \%)$ and chest pain $(30.61 \%)$ are the most common presentations. In Lok NS, Lau CP study dyspnea and palpitation were the most common symptoms. ${ }^{19}$ Gregory YH Lip described dyspnea (52\%), chest pain (34\%) and palpitation (24\%) as the presenting symptoms in emergency admissions in AF. We also noticed that the symptoms are of longer duration in rheumatic etiology and are of shorter duration in other causes.

In our study congestive heart failure was the most common associated condition, nearly in 50\% cases. CHF was a powerful independent predictor of the occurrence of AF in the Framingham study, in both symptomatic and asymptomatic LV dysfunction. AF is diagnosed in $10 \%$ to $35 \%$ of patients with CHF during the course of the disease and is related to the clinical severity of its symptoms. ${ }^{20}$

In the present study stroke is seen in $13.33 \%$ of cases only. In a study from Trieste, Italy, $34 \%$ of patients with chronic AF had a significantly higher rate of thrombo-embolism, suggesting that in addition to age, chronicity may be a risk factor for stroke in the lone AF population. ${ }^{21}$

\section{Conclusion:}

In summary it was concluded that, the prevalence of chronic AF is still more common below the age of 50 years in this part of our country despite of increase in prevalence of IHD and increase in life expectancy of average Indian citizen and this is mostly due to high prevalence of rheumatic heart disease in India. CHF is the most common associated condition with chronic AF.

\section{Acknowledgments:}

Residents, General M edicine 


\section{References:}

1. Go AS, Hylek EM, Phillips KA, Chang Y, Henault LE,Selby JV, Singer DE: Prevalence of diagnosed atrial fibrillation in adults: national implications for rhythm management and stroke prevention: The Anticoagulation and Risk Factors in Atrial Fibrillation (ATRIA) Study. JAM A. 2001; 285: 2370-2375.

2. Carson PE, Johnson GR, Dunkman WB, Fletcher RD, Farrell L, Cohn JN: The influence of atrial fibrillation on prognosis in mild to moderate heart failure: The V-HeFT Studies. The V-HeFT VA Cooperative Studies Group. Circulation. 1993; 87: VI102-VI110.

3. Dries DL, Exner DV, Gersh BJ, Domanski MJ, Waclawiw MA, and Stevenson LW: Atrial fibrillation is associated with an increased risk for mortality and heart failure progression in patients with asymptomatic and symptomatic left ventricular systolic dysfunction: A retrospective analysis of the SOLVD trials. Studies of Left Ventricular Dysfunction. J Am Coll Cardiol. 1998; 32: 695-703.

4. Maisel WH, Rawn JD, Stevenson WG: Atrial fibrillation after cardiac surgery. Ann Intern Med. 2001; 135: 1061-1073.

5. Rathore SS, Berger AK, Weinfurt KP, Schulman KA, Oetgen WJ, Gersh BJ, Solomon AJ: Acute myocardial infarction complicated by atrial fibrillation in the elderly: Prevalence and outcomes. Circulation. 2000; 101: $969-974$

6. Diker E, Aydogdu S, Ozdemir M, Kural T, Polat K, Cehreli S, Erdogan A, Goksel S: Prevalence and predictors of atrial fibrillation in rheumatic valvular heart disease. Am J Cardiol. 1996; 77: 96-98.

7. Krahn AD, Manfreda J, Tate RB, Mathewson FA, and Cuddy TE: The natural history of atrial fibrillation: Incidence, risk factors, and prognosis in the M anitoba Follow-Up Study. Am J M ed. 1995; 98: 476 484.

8. Robinson K, Frenneaux M P, Stockins B, Karatasakis G, Poloniecki JD, McKenna WJ: Atrial fibrillation in hypertrophic cardiomyopathy: A longitudinal study. J Am Coll Cardiol. 1990; 15: 1279-1285.

9. Wong CK, White HD, Wilcox RG, Criger DA, Califf RM, Topol EJ, Ohman EM: New atrial fibrillation after acute myocardial infarction independently predicts death: The GUSTO-III experience. Am Heart ]. 2000; 140: 878- 885

10. Buch $\mathrm{P}$, Friberg J, Scharling H, Lange $\mathrm{P}$, and Prescott E: Reduced lung function and risk of atrial fibrillation in the Copenhagen City Heart Study. Eur Respir J. 2003; 21: 1012-1016.
11. Gami AS, Pressman G, Caples SM, Kanagala R, Gard JJ, Davison DE, M alouf JF, Ammash NM , Friedman PA, Somers VK: Association of atrial fibrillation and obstructive sleep apnea. Circulation. 2004; 110: 364 $-367$.

12. Goldhaber SZ, Visani L, De Rosa M: Acute pulmonary embolism: Clinical outcomes in the International Cooperative Pulmonary Embolism Registry (ICOPER). Lancet. 1999; 353: 1386 - 1389.

13. Woeber KA: Thyrotoxicosis and the heart. N Engl J M ed. 1992; 327: 94 $-98$.

14. Wang TJ, Parise $H$, Levy D, D'Agostino RB Sr, Wolf PA, Vasan RS, Benjamin E): Obesity and the risk of new-onset atrial fibrillation. JAM A. 2004; 292: 2471-2477.

15. Naccarelli GV, Varker H, Lin J, Schulman KL. Increasing prevalence of atrial fibrillation and flutter in the United States. Am J Cardiol 2009; 104:1534-9

16. Lip GY. Golding DJ - A survey of atrial fibrillation in general practice. British J. of general practice. 1997; 47 (418) 285 - 289.

17. Lip GY, Beevers DG. ABC of atrial fibrillation: History, epidemiology, and importance of atrial fibrillation. BMJ 1995; 311:1361.

18. P.T. Onundarson, G.Thorgeirsson, E.Jonmundsson, N.Sigfusson and Th. Hardarson. Chronic atrial fibrillation - epidemiologic features and 14 year follow-up: A case control study. Eur Heart J. 1987; 8(5): 521-527.

19. Lok NS Lau Cp - Presentation and M anagement of patients admitted with atrial fibrillation. International Jr. of Cardiology. 1995; 48 (3): 271 278

20. SM Vaziri, MG Larson, EJ Benjamin, and D Levy Echocardiographic predictors of nonrheumatic atrial fibrillation. The Framingham Heart Study Circulation. 1994; 89:724-730.

21. Scardi S, M azzone C, Pandullo C, Goldstein D, Poletti A, Humar F. Lone atrial fibrillation: prognostic differences between paroxysmal and chronic forms after 10 years of follow-up. Am Heart J 1999; 137:686691. 